\title{
Distribution, Characterization of Mycobacterial Glycolipids and Host Responses
}

\author{
Nagatoshi Fujiwara
}

Additional information is available at the end of the chapter

http://dx.doi.org/10.5772/48301

\section{Introduction}

Robert Koch discovered the acid-fast bacterium that is the pathogenic germ of tuberculosis (TB) in 1882 [1]. TB is a major public health problem in the world and the leading cause of death from a single infectious agent. The World Health Organization estimates that one third of the world's population is infected with Mycobacterium tuberculosis, and annually reports the global burden of the disease caused by TB. Over 8 million new cases and nearly 1.5 million deaths from TB occur each year, presenting a significant threat to the world health [2]. The pathogenicity of mycobacteria is related to their ability to evade being ingested by macrophages, produce latent infection, and induce delayed-type hypersensitivity lesions such as granulomas. Moreover, the global spread of multi- and extensively drug-resistant TB (MDR-TB and $\mathrm{XDR}-\mathrm{TB}$, respectively) and the number of immunocompromised hosts, including victims of the human immunodeficiency virus (HIV) epidemic, are important problems [3].

The mycobacteria include the TB-causative acid-fast bacteria that are widely pathogenic to humans: M. tuberculosis, M. avium-intracellulare complex (MAC), M. leprae, and M. bovis, the source of the only available TB vaccine, Bacillus Calmette Guérin (BCG). The acid-fast bacteria are rich in lipids, and many mycoloyl glycolipids, such as cord factor/trehalose-6,6'dimycolate (TDM), phenolic glycolipid (PGL), sulfolipid (SL), glycopeptidolipid (GPL), phosphatidylinositol mannoside (PIM), lipomannan (LM), and lipoarabinomannan (LAM), are distributed in the cell wall [4-7]. Among them, glycolipids specific to the mycobacteria play a key role in the pathogenesis, because mycobacteria have large amounts of lipids that possess pleiotropic activities. The complex interaction between a range of mycobacterial components and the host cause the pathogenesis.

In this review, the distribution of major glycolipids in several Mycobacteria and structural analyses using mass spectrometry (MS) are described. MS and MS/MS are useful to analyze 
the glycosyl linkage, composition, and sequence of the sugar moiety. These results make it possible to discuss the heterogeneity and biosynthesis of glycolipids, and host responses to them. We hope that this review will promote better understanding of the structure-function relationships of glycolipids and open new avenues for prevention of infectious diseases.

\section{Distribution of glycolipids and phospholipids in mycobacteria}

The cell envelope surrounds the cytoplasm and is important for bacterial physiology and protection of microorganisms from their environment. Unlike other pathogenic microbes, the cell envelope of the acid-fast bacteria, including mycobacteria, is wax-like. The characteristic component is mycolic acids (MAs) which are $\alpha$-branched $\beta$-hydroxy fatty acids (FAs), and have species-specific carbon-chain lengths and subclasses ( $\alpha$, methoxy, keto, dicarboxy, epoxy, etc.). The total lipid fraction was extracted with chloroform/methanol (3:1 and 2:1 v/v) and developed by two-dimensional thin-layer chromatography (TLC). Many glycolipids and phospholipids were detected, as shown in Fig. 1. Some glycolipids, such as cord factor/TDM and trehalose 6-monomycolate (TMM), exist ubiquitously in mycobacteria, and other glycolipids, including SLs and penta-acyl trehalose, exist only in virulent strains [8]. In general, the mycobacterial species have heterogeneous compositions and concentrations of glycolipids. According to current models of the mycobacterial cell envelope, which are ultimately based on an idea of Minnikin [9], arabinogalactan-attached MAs are believed to form one highly-arranged leaflet of a second membrane-like structure adjacent to the cell-wall skeleton (CWS). Complemented by other lipids forming the outer leaflet, this structure represents a very hydrophobic barrier that is responsible for the resistance to certain drugs [10]. The free glycoconjugates of MA, in particular TMM and cord factor/TDM, appear to be more difficult to localize, and occasionally they are described or depicted as distributed on the cell surface or buried more deeply in the cell envelope. A proposed structure of the mycobacterial cell envelope is shown in Fig. $2[4,11,12]$.

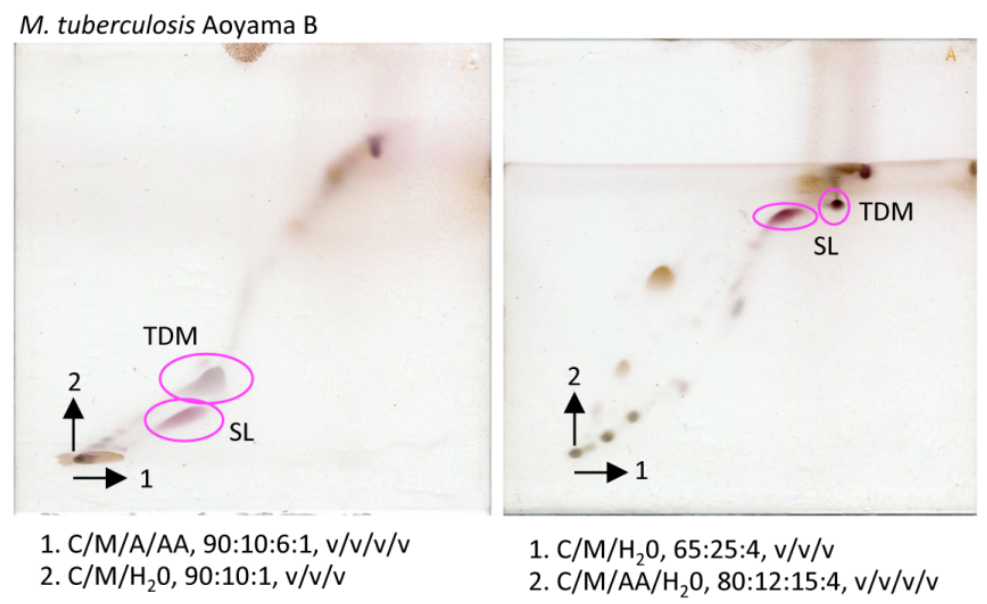

Figure 1. TLC of total lipids derived from Mycobacterium tuberculosis Aoyama B strain. 


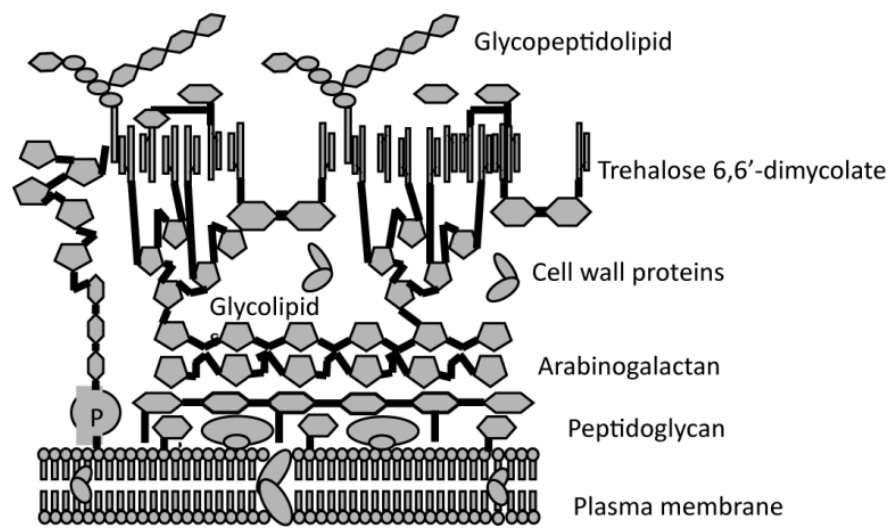

Figure 2. Schematic representation of mycobacterial cell envelope.

\section{Host responses to mycobacterial glycolipids}

Mycobacteria are intracellular pathogens. Mycobacterial infection has dual consequences for the host: development of inflammatory lesions and clearance of the pathogen. Genetic regulation and expression of cell-mediated immunity and delayed-type hypersensitivity play critical roles in the outcome. Cell-mediated immunity participates in host defense, whereas delayed-type hypersensitivity is involved in the development of granulomatous inflammation. After invasion to the host cell, the mycobacteria multiply inside macrophages. The mechanism of pathogenesis is focused on evading the host's killing system and induction of delayed-type hypersensitivity [13]. Certain cell wall glycolipids, such as cord factor/TDM, SL, and LAM [5-7], are involved in the host-pathogen interaction, and induce the primary host immune responses.

Peptides and proteins with a wide range of antigenic moieties are recognized by the host immune system using major histocompatibility complex (MHC) class I or II. The recognition of lipids is important for host defense against mycobacterial infection as well as other antigenic responses. Several bacterial lipid antigens are recognized by specific T cells. MA derived from mycobacteria is a lipid antigen that stimulates CD1b-restricted $T$ cells $[14,15]$. Other immunogenic mycobacterial glycolipids, glucose-6-monomycolate (GMM), PIM, and LAM, are available for loading onto CD1 molecules and recognized by specific T cells [16, 17].

\section{Mycoloyl glycolipids}

Acid-fast bacteria produce several mycolyl glycolipids that are composed of sugar and MA. The carbon-chain lengths and subclasses of MAs are species-specific. Nocardia, Rhodococcus, and Diezia species have short carbon-chain length MAs, and the subclass is mainly the $\alpha$ type. MAs of Mycobacterium species have long carbon-chains and are of various subclasses ( $\alpha$, methoxy, keto, dicarboxy, and epoxy types). In general, the average number of carbons in MAs increases from Dietzia, Rhodococcus, Nocardia, and Gordona to Mycobacteria. The MAs 
are extracted with $n$-hexane or chloroform after alkaline-hydrolysis of heat-killed bacteria, and the subclasses are detected by using TLC developed with methyl ester derivatives (Fig. 3). The molecular species of the MA subclasses are determined by matrix-assisted laser desorption/ionization time-of-flight mass spectrometry (MALDI-TOF MS) using an Ultraflex II (Bruker Daltonics, Billerica, MA, USA) with $10 \mathrm{mg} / \mathrm{ml}$ 2,5-dihydroxybenzoic acid (DHB) in chloroform-methanol $(1: 1, \mathrm{v} / \mathrm{v})$ as a matrix, and analyzed in Reflectron mode with an accelerating voltage operating in positive mode at $20 \mathrm{kV}$ (Fig. 4). The MAs with short carbon-chains can be analyzed by using gas-chromatography mass spectrometry GC/MS. The trimethylsilyl derivatives of MA methyl esters are volatile, and the GC/MS spectra show specific fragment patterns that are assigned to detailed structures (Fig. 5), although the MAs with long carbon chains are difficult to vaporize and detect by GC/MS [18-20]. In addition, MAs are analyzed by using high performance liquid chromatography (HPLC) [21]. The resolution of HPLC is poor compared to that of GC/MS. GMM, fructose-6-monomycolate (FMM), and mannose-6-monomycolate (MMM) are produced by acid-fast bacteria cultured with their respective carbon source: glucose, fructose, and mannose. The structures are composed of MAs attached to glucose, fructose, and mannose, respectively, at the C6 position [20, 22]. Recently, it was reported that M. tuberculosis produces GMM by transferring MA to glucose from cord factor/TDM, and thus evades the host immune system [23]. The molecular weights of mycoloyl glycolipids are measured by MALDI-TOF MS, and this information makes it possible to determine the combination of MA subclasses [24]. Cord factor/TDM is probably the most prominent and best-studied MA-containing compound of mycobacteria, and shows pleiotropic activities, including the development of granulomatous inflammation, anti-tumor immune response, and adjuvant effects based on the induction of proinflammatory and type 1 helper T cell (Th1)-related cytokines from host cells [25-27]. We demonstrated that administration of cord factor/TDM could induce delayed-type hypersensitivity-like lesions and foreign-body granulomas in euthymic and athymic mice, regardless of preimmunization with mycobacteria and cord factor/TDM. In fact, preimmunized mice challenged with cord factor/TDM developed more severe lesions than unimmunized mice. At the active lesion, CC-chemokines attracting monocytes, proinflammatory cytokines, and immunoregulatory cytokines were found. The inflammatory and cytokine responses were augmented in immunized mice challenged with cord factor/TDM. As a result, cord factor/TDM can induce both foreign body-type (nonimmune) and hypersensitivity-type (immune) granulomas by acting as a nonspecific irritant and T-cell-dependent antigen, and both nonimmune and immune mechanisms participate in granulomatous inflammation induced by mycobacterial infection [13, 28]. Moreover, rhodococcal cord factor/TDM induced milder granulomatous lesions than a mycobacterial one, implying that the proinflammatory responses induced by cord factor/TDM are in proportion to the carbon-chain length and subclasses of MAs in addition to carbon species [20,29]. Recently, it was clarified that macrophage-inducible C-type lectin (mincle) is an essential receptor for cord factor/TDM [30]. Mincle is a receptor for sugar, and our previous result showed that the proinflammatory responses are MA-dependent. I expect the discovery of other unknown receptors for cord factor/TDM in addition to mincle. 


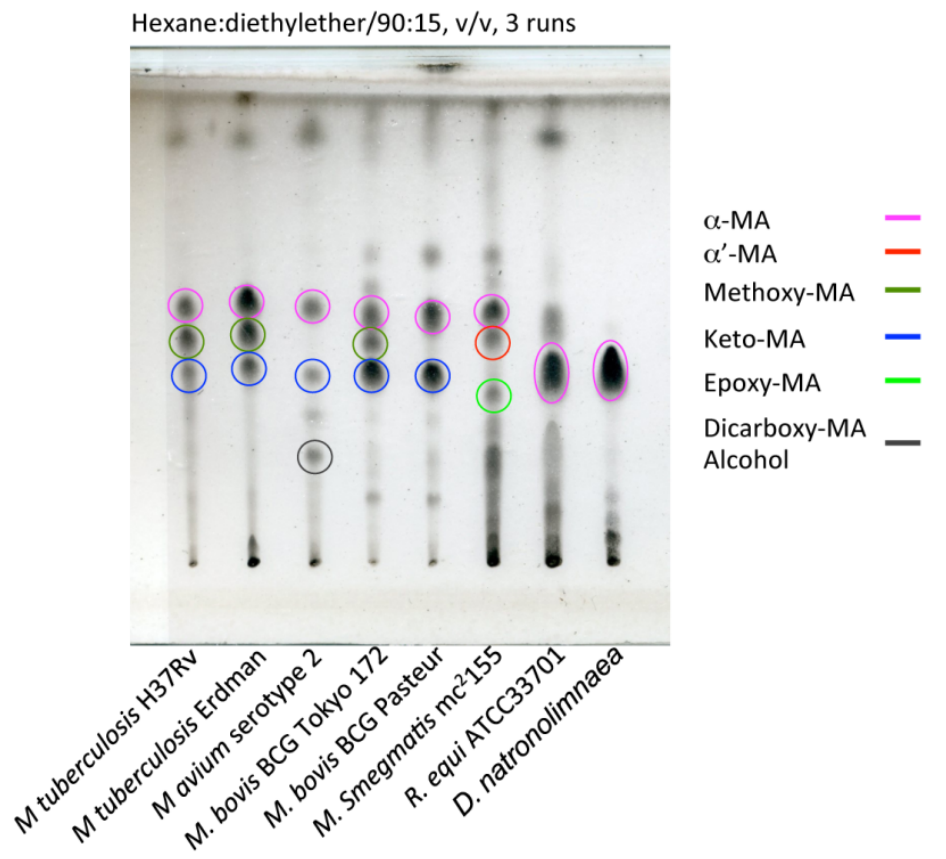

Figure 3. TLC of mycolic acid methyl esters derived from Mycobacterium, Rhodococcus, and Dietzia species.

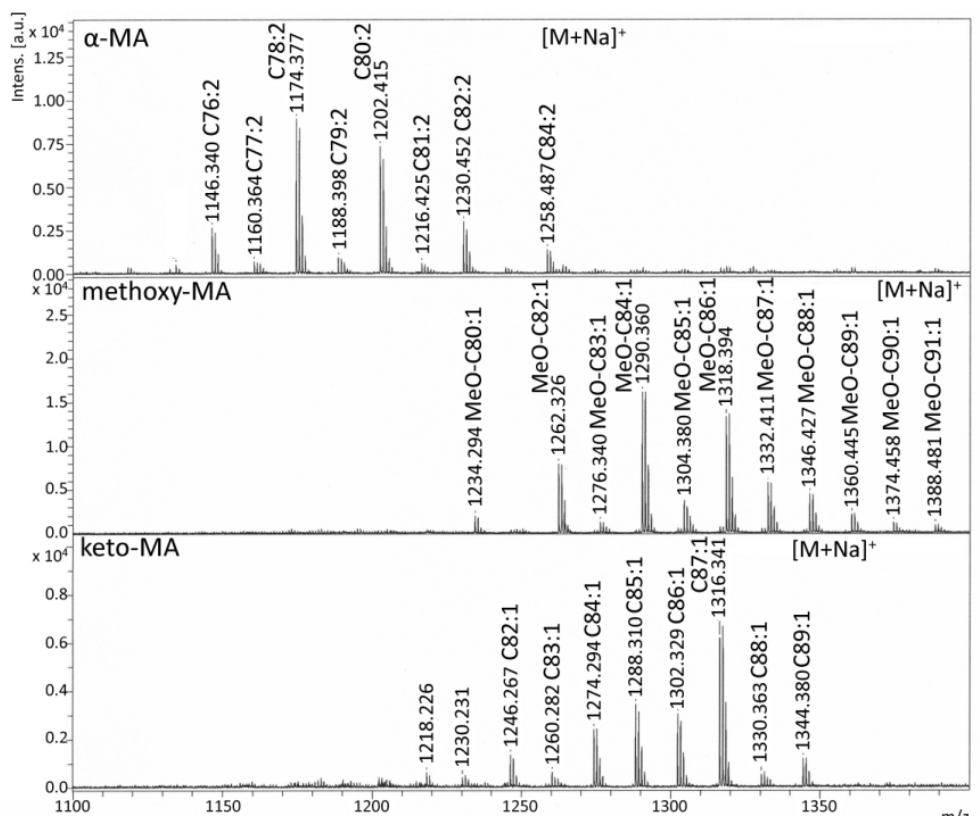

Figure 4. MALDI-TOF MS spectra of mycolic acid methyl ester subclasses from M. tuberculosis H37Rv. 

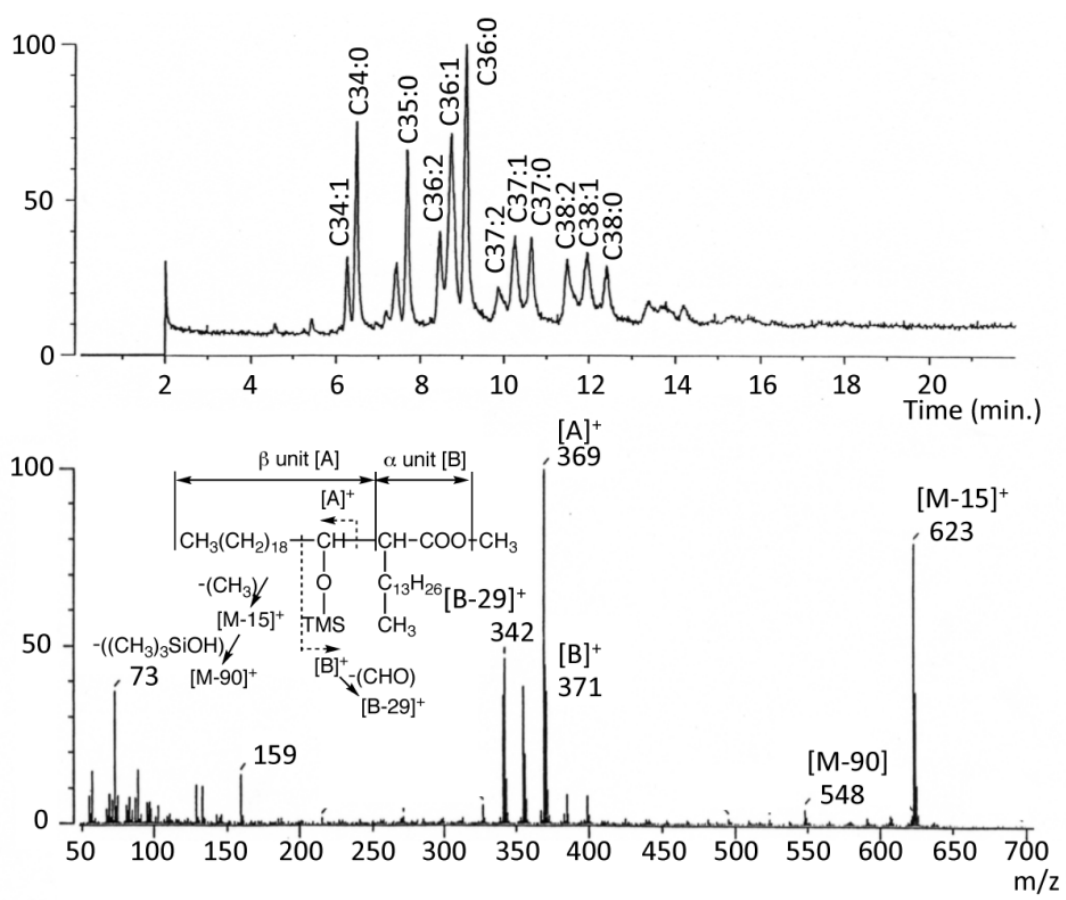

Figure 5. Total ion chromatogram and mass spectrum of mycolic acid trimethylsilyl derivatives from R. equi.

\section{Glycopeptidolipid (GPL)}

GPLs are produced by MAC, M. scrofulaceuem, M. chelonae, M. fortuitum, and M. smegmatis. Structurally, a GPL is composed of two parts, a common tetrapeptido-amino alcohol core and a serotype-specific oligosaccharide (OSE) elongated from 6-deoxy-talose (6-d-Tal). Dphenylalanine-D-allo-threonine-D-alanine-L-alaninol (D-Phe-D-allo-Thr-D-Ala-L-alaninol), which is modified with an amido-linked 3-hydroxy or 3-methoxy C26-C34 FA at the Nterminal of D-Phe; D-allo-Thr and terminal L-alaninol are further linked to a 6-d-Tal and 3,4-di-O-methyl rhamnose (3,4-di-O-Me-Rha), respectively [31]. This portion is common to all serotypes, and is called the serotype-nonspecific GPL (apolar GPL), which exhibits antigenicity [11]. Serotype-specific GPLs (polar GPLs) are further glycosylated with a variable haptenic OSE at 6-d-Tal. We determined the structures of the serotype 7, 13, and 16 GPLs and identified the gene clusters completing the OSE biosynthesis [32-34]. In addition, two methyltransferase genes of serotype 7- and 12-specific GPL biosynthesis were characterized [35]. The standard technique to classify MAC strains has employed serologic typing based on the OSE residue of the GPL. Recently, the biosynthetic pathway of various haptenic OSEs has been explored, and the genes encoding the pathways have been identified and characterized [36-38]. At present, 31 distinct serotype-specific polar 
GPLs have been identified biochemically, and the complete structures of 17 GPLs are defined [12, 33]. The GPL present on the cell wall is considered to affect colony morphology. The MAC colony phenotype spontaneously changed from a smooth to a rough type, and this was due to a mutation lacking GPLs [39, 40]. The polar GPLs produced by MAC species are of particular interest because they are considered to be correlated with the physiology of the bacteria and the host responses to MAC infection, for example, colony morphology, sliding motility, biofilm formation, immune modulation, and virulence [40-43].

We have demonstrated the applicability of serodiagnosis of MAC pulmonary diseases using the GPL and GPL core antigens, and have also shown that the levels of GPL and GPL core antibodies reflect disease activity [44-46]. The GPLs are produced by MAC species but are absent in M. tuberculosis, making it possible to distinguish MAC from tuberculous mycobacteria [44, 47]. An anti-GPL antibody is produced in the sera of patients and the level reflects the extent of disease, which is useful in diagnosis and treatment $[48,49]$. GPLs are one of the immunologically active molecules characteristic of MAC, and serotype-specific GPLs participate in the pathogenesis and immunomodulation in the host $[50,51]$. It has been reported that the GPL core plays a role in suppression of mitogen-induced blastogenic response in spleen cells [52]. In addition, the immunomodulating activity of GPL on macrophage functions is serotypedependent [53]. The serotype 4 GPL promotes phagocytosis and inhibits phagosomelysosome (P-L) fusion, whereas the GPLs of serotypes 9 and 16 exhibit no effect on phagocytosis and P-L fusion. The serotype 8 GPL shows concomitant stimulation of both phagocytosis and P-L fusion. Because the GPL core, but not OSE, is common in all serotypes, the OSE of GPL may be involved in the mechanism of inhibition of P-L fusion, which is mediated through mannose receptors of macrophages [54]. The serotype $4 \mathrm{GPL}$ inhibits the lymphoproliferative response to mitogens [51]. Thus, host responses to GPLs vary with the MAC serotype. It is reported that the uptake by and growth in macrophages of a MAC mutant with a gene in the GPL synthesis pathway inactivated by a transposon insertion were decreased [55]. The pathogenicity of GPL may comprise both a common peptide core and an OSE elongated from 6-d-Tal. The GPL is a pleiotropic molecule and participates in the pathogenesis of MAC disease. Elucidation of the structure-activity relationship of GPL is required for a better understanding of the pathogenesis.

\section{Structural analysis of GPL}

The polar GPL is species-specific in the portion of the OSE. MS is very useful to analyze the structure of OSE sequences and linkage positions in addition to total molecular weight. In this review, I describe detailed methods and results of structural analyses of some GPLs. The procedure for structural analysis of OSE is summarized in Fig. 6. 
- Cultivation of Mycobacterium avium-intracellulare complex

Middlebrook $7 \mathrm{H} 11$ agar, $37^{\circ} \mathrm{C}, 2-3$ weeks

- Extraction of lipids fraction (Chloroform/Methanol, 2:1 v/v)

- Mild alkaline hydrolysis (0.2 N KOH)

- Purification of glycopeptidolipid (GPL)

- Structural analysis of GPL

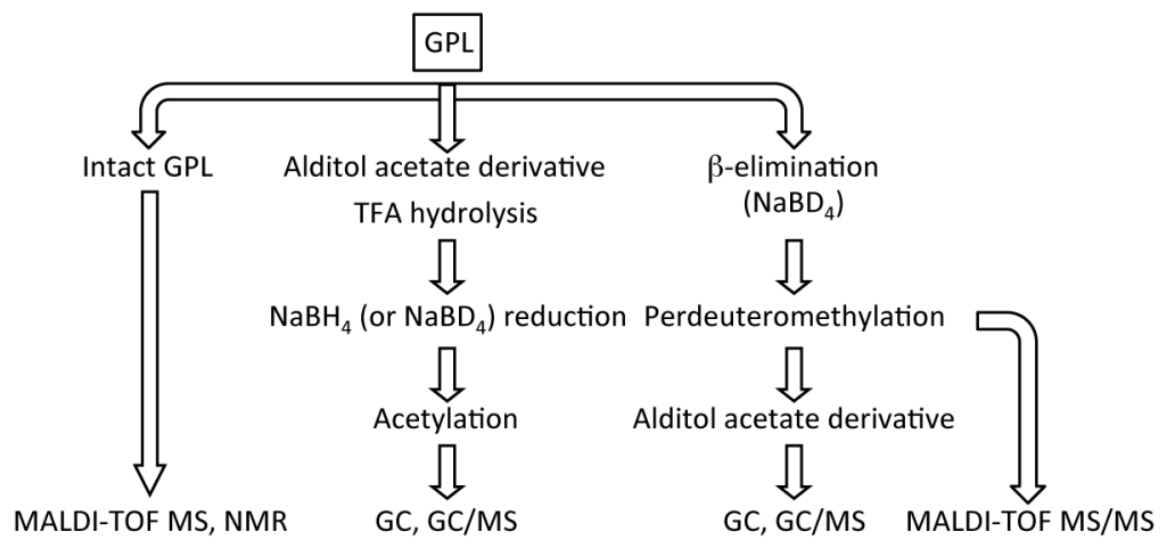

Figure 6. Procedure for structural analyses of OSE.

\subsection{Preparation of GPL}

MAC was grown on Middlebrook 7H11 agar (Difco Laboratories, Detroit, MI, USA) with $0.5 \%$ glycerol and $10 \%$ Middlebrook OADC enrichment (Difco) at $37^{\circ} \mathrm{C}$ for $2-3$ weeks. Heatkilled bacteria were sonicated, and total lipids were extracted with chloroform-methanol $(2: 1, \mathrm{v} / \mathrm{v})$. The total lipids were hydrolyzed with $0.2 \mathrm{~N}$ sodium hydroxide in methanol at $37^{\circ} \mathrm{C}$ for $2 \mathrm{~h}$, followed by neutralization with $6 \mathrm{~N}$ hydrochloric acid. Alkaline-stable lipids were partitioned by a two-layer system with chloroform-methanol $(2: 1, \mathrm{v} / \mathrm{v})$ and water. The organic phase was evaporated and precipitated with acetone to remove any acetoneinsoluble components. The supernatant was partially purified with a Sep-Pak Silica Cartridge (Waters Corporation, Milford, MA, USA). The GPL was completely purified by preparative TLC of silicagel G (Uniplate; $20 \times 20 \mathrm{~cm}, 250 \mu \mathrm{m}$; Analtech, Inc., Newark, DE, USA). The TLC plate was developed with chloroform-methanol-water (65:25:4 and 60:16:2, $\mathrm{v} / \mathrm{v})$, until a single spot was obtained.

\subsection{Preparation of OSE moiety}

$\beta$-Elimination of the GPL was performed with alkaline borohydride, and the OSE elongated from D-allo-Thr was released $[34,56]$. The GPL was stirred in a solution of 
equal volumes of ethanol and $10 \mathrm{mg} / \mathrm{ml}$ sodium borodeuteride in $0.5 \mathrm{~N}$ sodium hydroxide at $60^{\circ} \mathrm{C}$ for $16 \mathrm{~h}$. The reaction mixture was decationized with Dowex 50W X8 beads (Dow Chemical Company, Midland, MI, USA), and evaporated under nitrogen to remove boric acid. After partition into two layers of chloroform-methanol $(2: 1, \mathrm{v} / \mathrm{v})$ and water, the upper aqueous phase was recovered and evaporated, and the OSE was purified as an oligoglycosyl alditol.

\subsection{Molecular weight of intact GPL}

The molecular species of the intact GPL was determined by MALDI-TOF MS. One $\mu \mathrm{g}$ of the GPL dissolved with chloroform-methanol $(2: 1, \mathrm{v} / \mathrm{v})$ was applied to the target plate, and $1 \mu \mathrm{l}$ of $10 \mathrm{mg} / \mathrm{ml}$ DHB in chloroform-methanol $(1: 1, \mathrm{v} / \mathrm{v})$ was added as a matrix. The intact GPL was analyzed in the Reflectron mode with an accelerating voltage operating in positive mode at $20 \mathrm{kV}$ [57]. The peak ions of intact GPL were detected in sodium adduct form, $[\mathrm{M}+\mathrm{Na}]^{+}$as the main molecular-related ion; representative spectra of some GPLs are shown in Fig. 7. The mass numbers identified the proposed structures of each GPL.

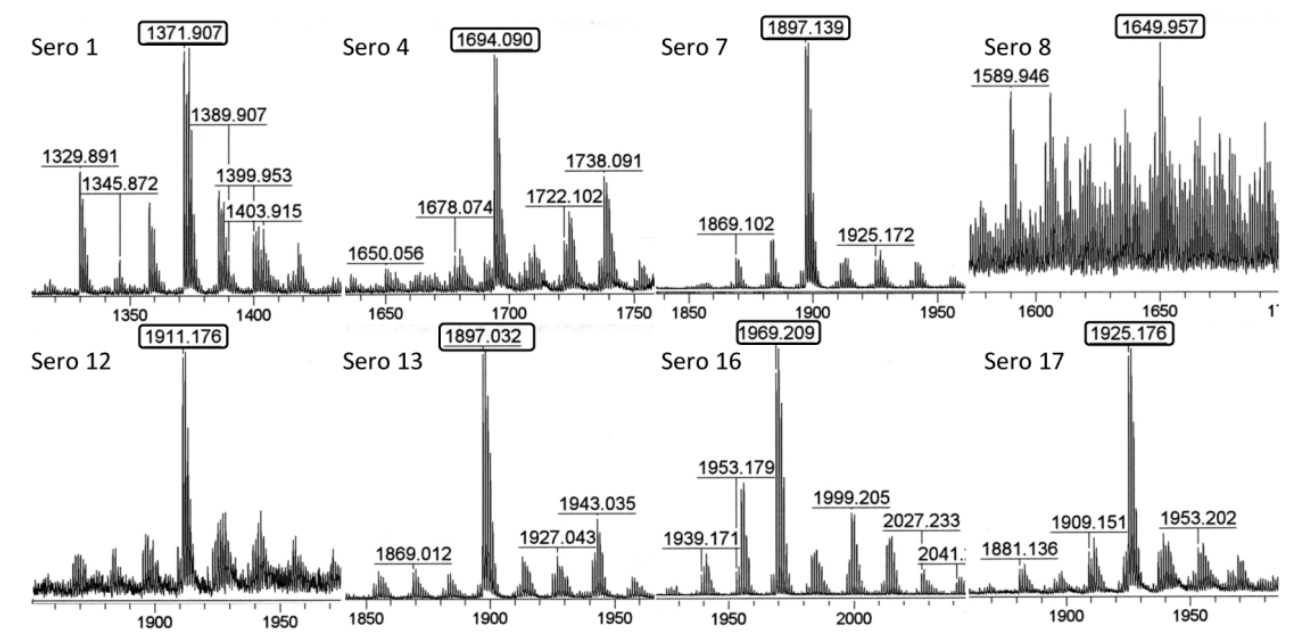

Figure 7. MALDI-TOF MS spectra of representative GPLs.

\subsection{Glycosyl sequences of OSE.}

The molecular weight of the OSE portion is measured by MALDI-TOF MS. The OSE and 10 $\mathrm{mg} / \mathrm{ml} \mathrm{DHB}$ were dissolved in ethanol-water $(3: 7, \mathrm{v} / \mathrm{v})$ and applied to the target plate 
according to the method for intact GPL. To determine the glycosyl sequence of the OSE, MALDI-TOF MS/MS analysis of the oligoglycosyl alditol from the OSE was performed. The spectrum afforded the molecular ion $[\mathrm{M}+\mathrm{Na}]^{+}$, together with the characteristic mass increments in the series of glycosyloxonium ions formed on fragmentation at each glycosyl linkage from both terminal sugars to their opposites, respectively. It was shown the representative assignments of intact serotype 13 GPL and its OSE with the proposed structure in Fig. 8.

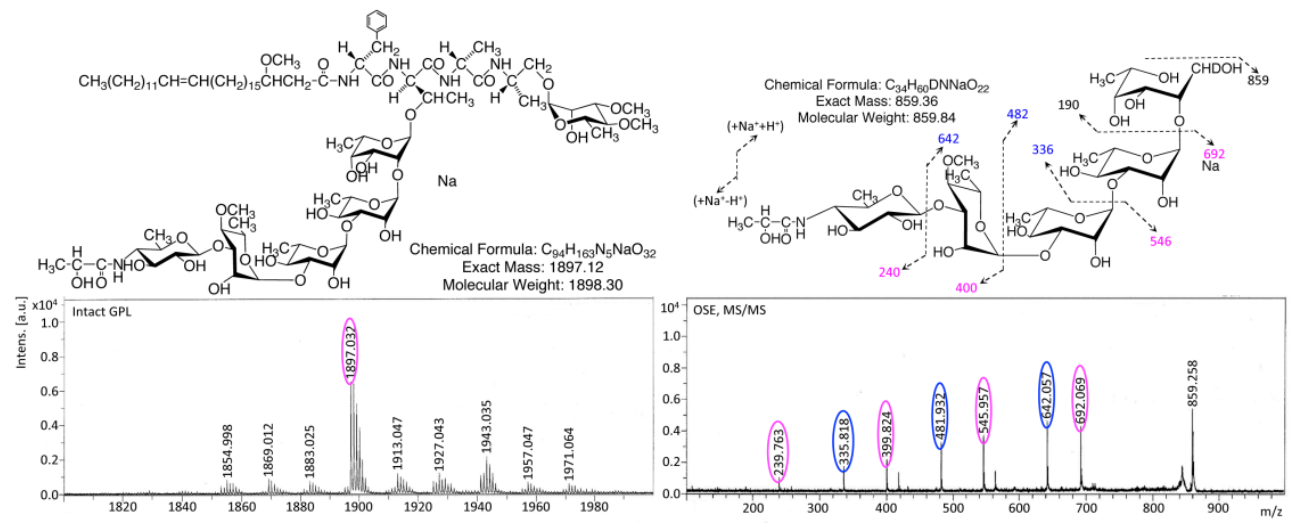

Figure 8. MALDI-TOF MS and MS/MS spectra of serotype $13 \mathrm{GPL}$. The molecular weight of the intact GPL was detected as m/z 1897 for [M+Na] ${ }^{+}$and fixed the proposed structure. The MS/MS spectra clearly show that the each ion was assigned to the fragmentation at each glycosyl linkage from both terminal sugars to their opposites, respectively.

\subsection{GC/MS of carbohydrates}

To determine the glycosyl composition and linkage position, GC/MS of partially methylated alditol acetate derivatives was performed. Perdeuteromethylation was conducted by the modified procedure of Hakomori [34,58]. The OSE was dissolved with a mixture of dimethylsulfoxide and sodium hydroxide, followed by the addition of deuteromethyl iodide. After stirring at room temperature for $15 \mathrm{~min}$, the reaction mixture was separated by a twolayer system of water and chloroform. The chloroform-containing perdeuteromethylated OSE layer was collected, washed twice with water, and evaporated completely. Partially deuteromethylated alditol acetate derivatives were prepared from perdeuteromethylated OSE by hydrolysis with $2 \mathrm{~N}$ trifluoroacetic acid at $120^{\circ} \mathrm{C}$ for $2 \mathrm{~h}$, reduction with $10 \mathrm{mg} / \mathrm{ml}$ sodium borodeuteride at $25^{\circ} \mathrm{C}$ for $2 \mathrm{~h}$, and acetylation with acetic anhydride at $100^{\circ} \mathrm{C}$ for $1 \mathrm{~h}$ [34, 59]. GC/MS was performed using a fused capillary column (SP-2380 and Equity-1; $30 \mathrm{~m}, 0.25 \mathrm{~mm}$ ID, Supelco, Bellefonte, PA). The linkage positions were acetylated, and no related positions were previously deuteromethylated. The linkage positions were assigned by the fragmentation patterns of partially deuteromethylated alditol acetate derivatives and retention time of the peaks. The representative fragmentation patterns of partially methylated alditol acetate derivatives are shown in Fig. 9. 
1,3,4,5-tetra-O-deuteromethyl-2-O-acetyl-6-deoxy-talitol

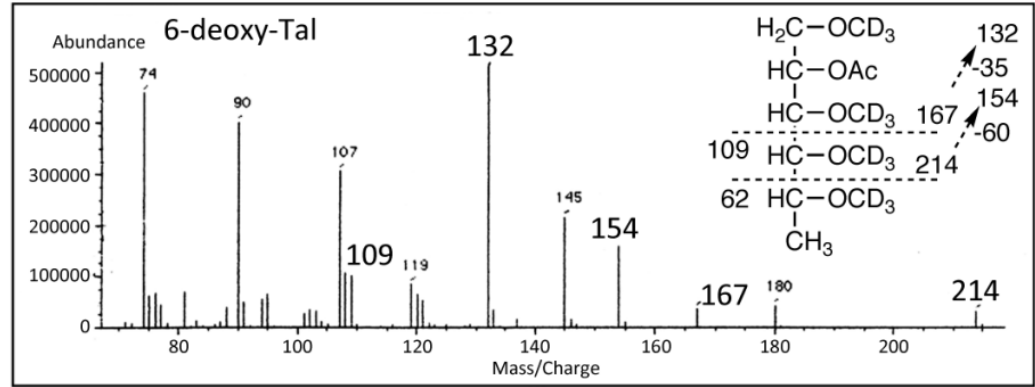

2,4-di-O-deuteromethyl-1,3,5-tri-O-acetyl-rhamnitol
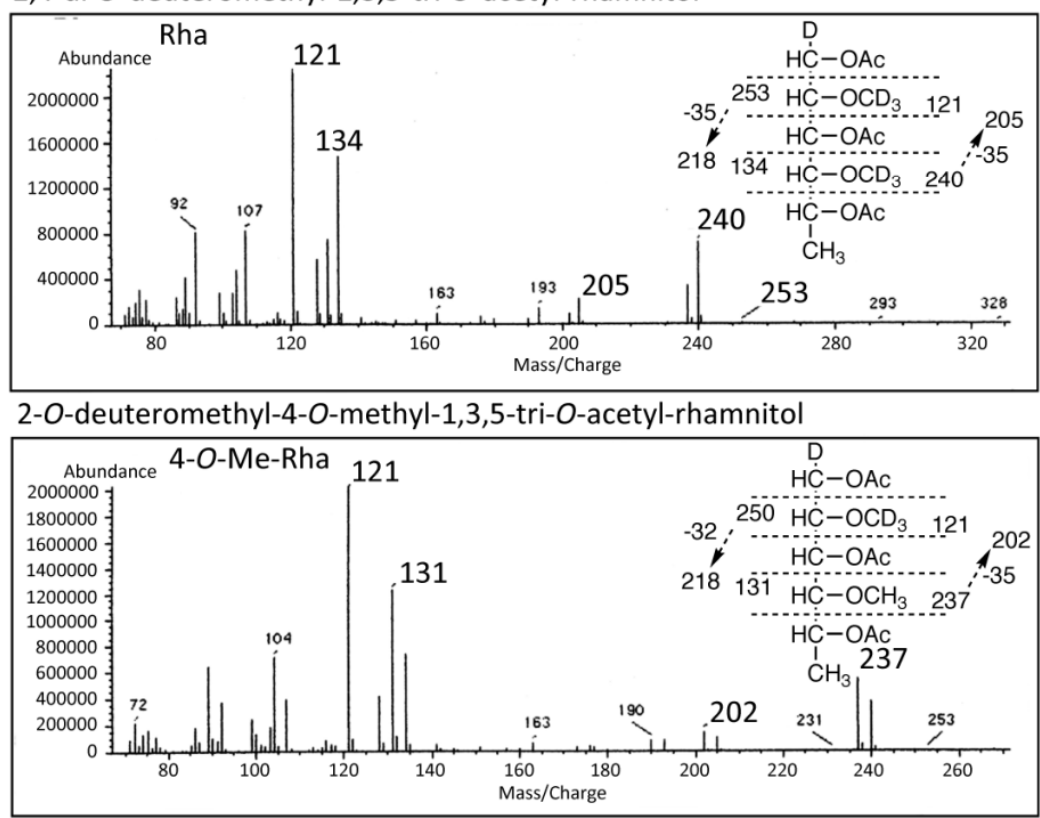

Figure 9. Representative mass spectrum of partially deuteromethylated alditol acetate derivatives.

\subsection{Nuclear magnetic resonance (NMR) of GPL}

The OSE was dissolved in deuterium oxide. To define the anomeric configurations of each glycosyl residue, ${ }^{1} \mathrm{H}$ and ${ }^{13} \mathrm{C}$ nuclear magnetic resonance (NMR) was employed. Both homonuclear correlation spectrometry (COSY) and ${ }^{1} \mathrm{H}$-detected $\left[{ }^{1} \mathrm{H},{ }^{13} \mathrm{C}\right]$ heteronuclear multiple-quantum correlation (HMQC) were performed as described previously [34, 56]. The ${ }^{1} \mathrm{H}$ NMR and ${ }^{1} \mathrm{H}-{ }^{1} \mathrm{H}$ homonuclear COSY analyses of the OSE derived from the GPL revealed distinct anomeric protons with corresponding $\mathrm{H} 1-\mathrm{H} 2$ cross-peaks in the low-field region, and the chemical shift and coupling constant are indicative of $\alpha$-anomers and a $\beta$ hexosyl unit, respectively. 


\section{Biosynthesis gene of GPL}

\subsection{Isolation of cosmid clones carrying $r t f A$ gene and sequence analysis}

First, we constructed the M. intracellulare cosmid library. Genomic DNA of MAC was prepared by mechanical disruption of bacterial cells, which was accomplished by homogenizing a bacterial pellet with glass beads in phosphate-buffered saline, followed by phenol-chloroform extraction, and precipitation with ethanol. Genomic DNA fragments randomly sheared to $30-50 \mathrm{~kb}$ fragments during the extraction process were fractionated and electroeluted from agarose gels using Takara Recochip (Takara, Kyoto, Japan). These DNA fragments were rendered blunt-ended using T4 DNA polymerase and dNTPs, followed by ligation to dephosphorylated arms of pYUB412 (XbaI-EcoRV and EcoRV-XbaI). After in vitro packaging using Gigapack III Gold extracts (Stratagene, La Jolla, CA, USA), recombinant cosmids were introduced into the E. coli STBL2 [F-morA D (mcrBC-hsdRMSmrr) endA1 recA1 lon gyrA96 thi supE44 relA1 1- D (lac-proAB)]. PCR was used to isolate cosmid clones carrying the rhamnosyltransferase $(r t f A)$ gene with primers $r t f A-\mathrm{F}\left(5^{\prime}\right.$ TTTTGGAGCGACGAGTTCATC- $3^{\prime}$ ) and $r t f A-R$ (5'-GTGTAGTTGACCACGCCGAC-3'). RtfA encodes an enzyme responsible for the transfer of Rha to 6-d-Tal in the OSE [38, 60]. We isolated the cosmid clones \#49 (accession no. AB274811) and \#253 (accession no. AB355138), which are responsible for the biosynthesis of GPL 7 and 16, respectively. The insert of a cosmid clone was sequenced using a BigDye Terminator v3.1 Cycle Sequencing Kit (Applied Biosystems, Foster City, CA, USA) and an ABI Prism 310 gene analyzer (Applied Biosystems). The putative function of each open reading frame (orf) was identified by similarity searches between the deduced amino acid sequences and known proteins using BLAST (http://www.ncbi.nlm.nih.gov/BLAST/) and FramePlot (http://www.nih.go. jp/ jun/cgi-bin/frameplot.pl), and the DNASIS computer program (Hitachi Software Engineering, Yokohama, Japan). The similarity of protein sequences of each ORF was compared to those of serotype 2, 4, 7, and 16 GPLs, and the genetic maps for GPL biosynthetic cluster are summarized in Fig. 10 [32, 36, 61]. The OSE of serotype 1 GPL produced by $M$. avium serotype 1 strain is composed of $\alpha$-L-Rha- $(1 \rightarrow 2)-6-\mathrm{d}-\mathrm{L}-\mathrm{Tal}$, which is the core OSE of all serotypes [12]. M. avium serotype 1 strain (NF113) was transformed with pYUB412-cosmid clone \#253 containing the serotype 16-specific gene cluster. The transformant produced a serotype 16 GPL with a different Rf value on TLC compared to serotype 1 GPL. The molecular weights of intact GPLs and the fragment patterns of their OSEs were completely equivalent to the serotype 16 GPL. Next, we identified some orf functions of $\# 253$. We hypothesized that orf1, 16, and 17 in \#253 were correlated with the glycosyltransferase by the similarity of ORF sequences, in addition to $r t f A$. They were compared to the productive GPLs of serotype 1 transformants inserted with the combination of orf1, 16, and 17. We determined that orf1, 17, and 16 were responsible for the elongation from 6-d-Tal-Rha to 6-d-Tal-Rha-Rha-Rha-Rha, and that these glycosyltransferases operated in this order, as shown in Fig. 11. After the elongation of an OSE, the OSE may be modified by aminotransferase, methyltransferase, and acyltransferase, and serotype 16 GPL may be completed. 
(A) M. avium strain 724 (serotype 2)

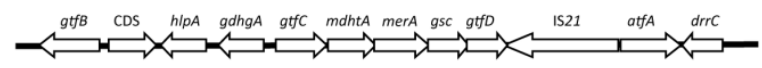

(B) M. avium strain A5 (serotype 4)

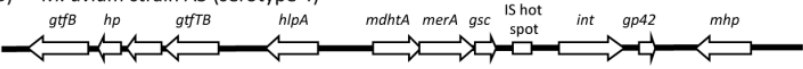

(C) M. Intracellulare ATCC 35847 (serotype 7)

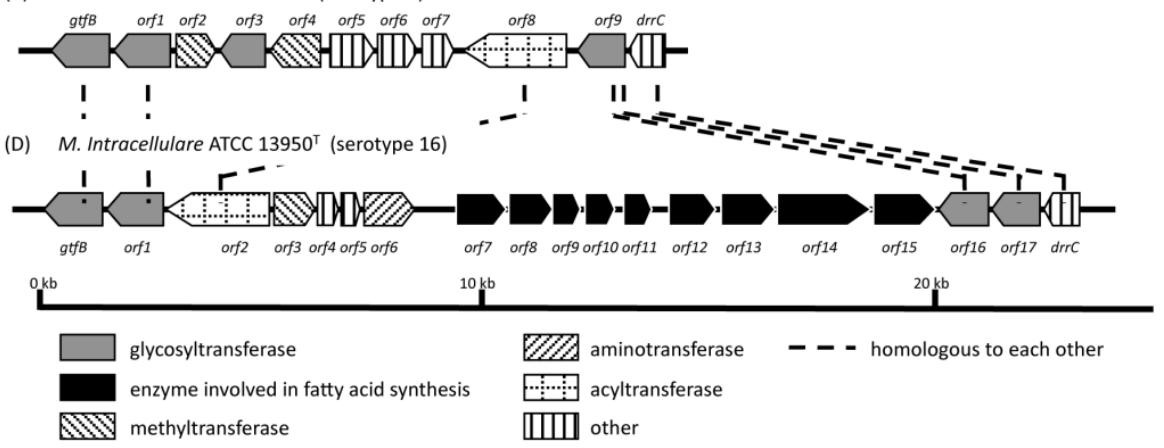

Figure 10. Comparison and overview of genetic maps of GPL biosynthetic cluster. (A), M. avium strain 724 (serotype 2, accession no. AF125999); (B), M. avium strain A5 (serotype 4, accession no. AY130970); (C), M. intracellulare ATCC 35847 (serotype 7, accession no. AB274811); (D), M. intracellulare ATCC $13950^{\mathrm{T}}$ (serotype 16, accession no. AB355138).

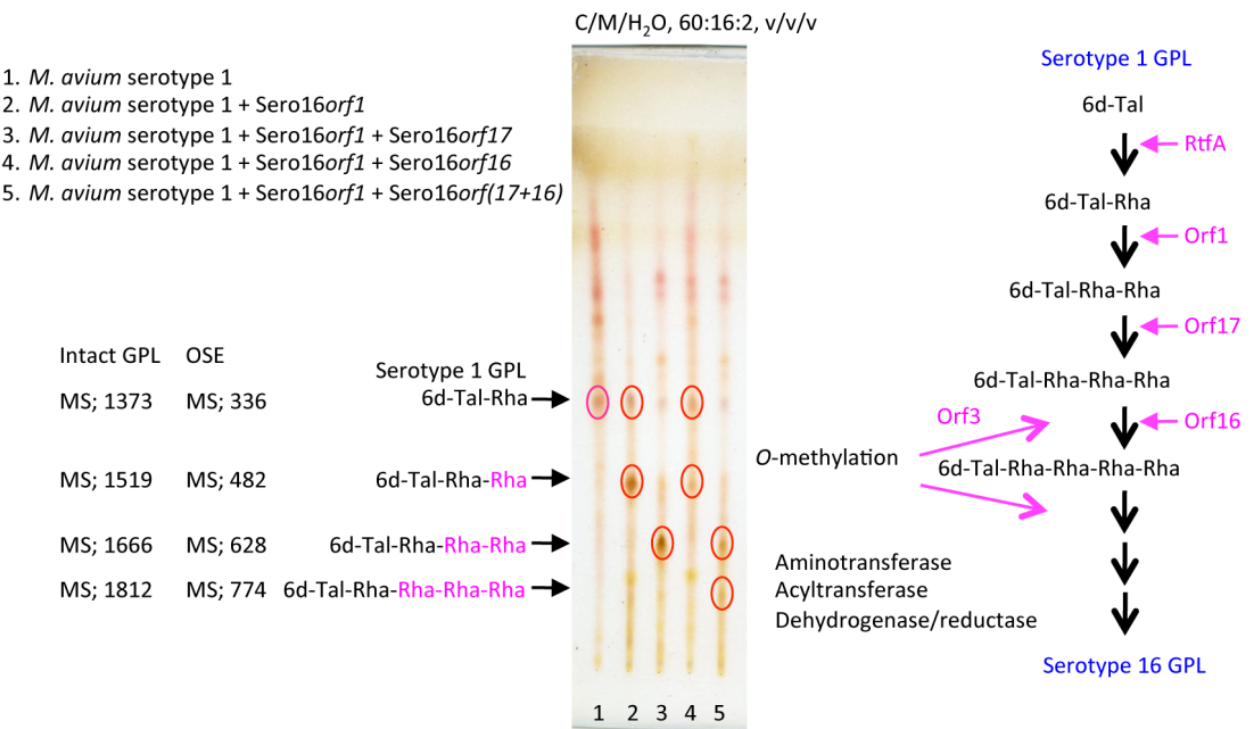

Figure 11. Proposed elongation of OSE in serotype 16 GPL. 


\subsection{Native conformation of GPL and host response}

The native GPL was purified without alkaline treatment. The native GPLs were detected on TLC as several spots that expanded broadly and had different Rf values from that of the alkaline-treated GPL (Fig. 12). Alkaline treatment converged these spots into one spot. It was reported that the native GPLs were modified by several $O$-acetylations in the OSE portion and the alkaline treatment removed the acetylated groups [23, 33]. We are now analyzing in detail the positions and numbers of $O$-acetylations in the OSE by using MALDI-TOF MS/MS.

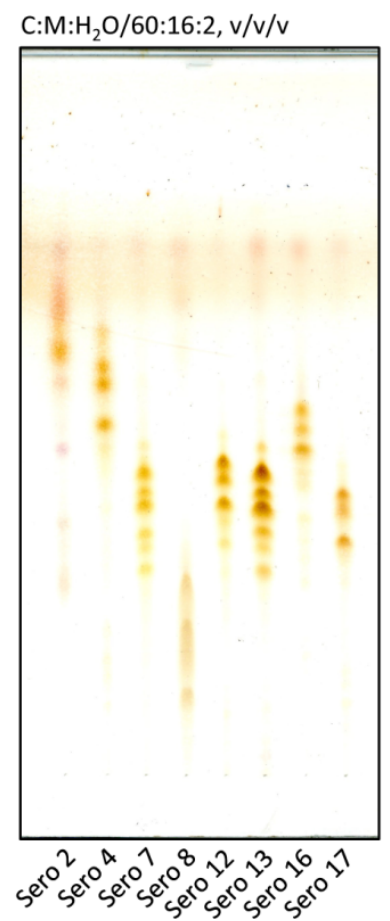

Figure 12. TLC of some native GPL fractions (non-alkali-treated).

The importance of Toll-like receptor (TLR)-mediated responses has been studied in tuberculous infections. Means et al. reported that M. tuberculosis activated both TLR2 and TLR4, whereas heat-killed M. tuberculosis and MAC activated only TLR2 [62]. It was observed that MyD88- and TLR2-deficient mice have increased susceptibility to MAC infection compared to TLR4-deficient and wild-type mice [63]. These lines of evidence suggest that TLRs are related to host recognition of the MAC components containing GPLs and affect MAC infections. To clarify the host recognitions of GPLs via TLRs, we stimulated HEK-blue-2, and -4 cells (InvivoGen, San Diego, CA, USA) with native and alkaline-treated GPLs. HEK-blue-2 and -4 cells are HEK293 cells stably transfected with multiple genes for recognition of TLR2 and TLR4 (including the co-receptors MD2 and CD14). The native GPL 
significantly activated HEK-blue-2 cells in a dose-dependent manner, but HEK-blue-4 cells did not respond (Fig. 13). The alkaline-treated GPL without $O$-acetylation did not activate either HEK-blue-2 or -4 cells. Re-acetylated alkaline-treated GPLs with O-acetyl groups substituted for all hydroxy groups of the OSE activated HEK-blue-2 cells, although the level of activation was lower than that of the native form. Moreover, we confirmed that only the native GPL stimulated mouse bone marrow-derived macrophages via TLR2 by using C57BL/6 and TLR2 knockout mice. Brennan and Goren first proposed that de-acetylated GPLs as alkaline-stable lipids, made it possible to classify serotyping [12, 31]. Schorey and colleagues clarified that serotype 1 and 2 GPLs can function as TLR2 agonists and promote macrophage activation in a TLR2 and MyD88-dependent pathway [64, 65]. They reported that the acetylated and methylated groups of GPLs were necessary for GPL-TLR2 interaction as a molecular requirement. Taken together with our results, native GPLs are a TLR2 agonist, and it may be important for GPL-TLR2 interaction to balance the hydrophobicity and hydrophilicity of the GPL molecules.

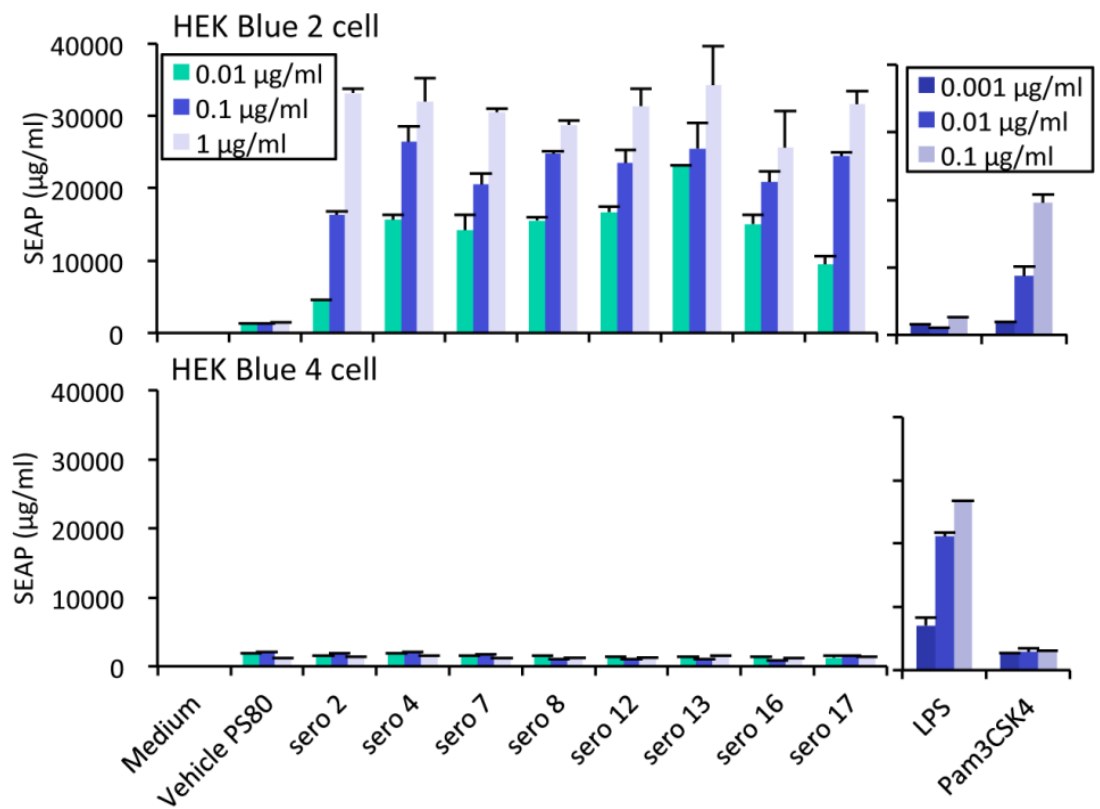

Figure 13. Native GPLs activate cells through TLR2.

\section{Sulfolipid (SL)}

Mycobacterial SLs are classified into three types by the number of attached short acyl chains. SL-1 is the predominant type, and SL-2 and -3 are intermediate types. The structure of SL-1 was identified as 2-palmitoyl(stearoyl)-3-phthioceranoyl-6,6'-bishydroxyphthioceranoyl-trehalose-2'-sulfate $[66,67]$. The presence of SLs in mycobacteria is strain-specific. Several studies have demonstrated a significant relationship between SL-1 
and virulence, such as the amount of SL-1 biosynthesis in virulent strains, and the inhibition of P-L fusion in macrophages by SL-1. SL-1 modulates superoxide release and secretion of interleukin (IL)- $1 \beta$ and tumor necrosis factor (TNF)- $\alpha$ by blocking activation of human macrophages and neutrophils $[68,69]$. In contrast to these studies, it has been reported that pks2 disruption and SL-1 deficiency do not significantly affect the replication, persistence, and pathogenicity of $M$. tuberculosis in mice, guinea pigs, or cultured macrophages [70, 71]. The pathogenicity of SL-1 is controversial. SL-1 does not induce granulomatous inflammation, but rather inhibits it and the release of TNF- $\alpha$ induced by cord factor/TDM [72]. SL-1 could contribute to virulence at an early stage of mycobacterial infection by counteracting the immunopotentiating effect of cord factor/TDM. On the other hand, it is reported that SL-3, 2-palmitoyl(stearoyl)-3-hydroxyphthioceranoyl-trehalose-2'-sulfate, is mainly recognized by CD1b-restricted $\mathrm{T}$ cells as a lipid antigen. The other tetraacylated and triacylated SLs (SL-1 and -2) were unable to stimulate diacylated SL (SL-3)-specific T cell clones, which implies that immunogenic SL-3 are not generated inside the antigen-presented cells [73]

SLs of M. tuberculosis have been implicated in the virulence of this organism by inhibiting the P-L fusion in macrophages, thus probably promoting the intracellular survival of $M$. tuberculosis, but the pathogenic role remains controversial. The gene, pks2, responsible for SL synthesis was identified and disrupted [74]. The $p k s 2$ mutant defective in an early step of SL biosynthesis had no obvious growth defect in infected mice. By contrast, growth of a strain lacking MmpL8, a transporter of SL in M. tuberculosis, was highly attenuated in a mouse model of tuberculosis [70]. Although initial replication rates and containment levels of the MmpL8 mutant were identical, compared with the wild type, a significant attenuation of the mutant strain in time-to-death was observed. Early in infection, differential expression of cytokines and cytokine receptors revealed that the mutant strain less efficiently suppresses key indicators of a Th1-type immune response, suggesting an immunomodulatory role for SLs in the pathogenesis of tuberculosis [75].

Recently, Kummer et al. demonstrate that PapA2 and PapA1 are responsible for the sequential acylation of SL1 biosynthesis. Disruption of papA2 and papA1 in M. tuberculosis confirmed their essential role in SL-1 biosynthesis and their order of action. BALB/c mice infected by aerosol with wild-type, $\triangle p a p A 2$, and $\triangle p a p A 1$ mutants showed no significant difference in the ability of the bacteria to grow or persist through the time to death of the mice. The loss of SL-1 did not appear to affect bacterial replication or trafficking. They suggested that the functions of SL-1 are specific to human infection [76].

\section{Phenolic glycolipid (PGL)}

The glycosylated phenolphthiocerol dimycocerosates (PDIM), so-called PGLs, are produced by a limited group of mycobacterial species, and most of them are pathogenic in humans [77]. PGL is distributed in $M$. leprae as a unique antigen, and inhibits the lymphoproliferative responses and suppresses monocyte oxidative responses [78-80]. It has also shown that disruption of PGL synthesis results in loss of the virulent phenotype 
without significantly affecting the bacterial load during disease in experimental models using mice and rabbits, and loss of PGL was found to correlate with an increase in the release of the pro-inflammatory cytokines in vitro [81, 82]. A PGL purified from M. leprae has been used as antigen in an enzyme-linked immunosorbent assay. Antibodies directed against the lipid were detected in sera of leprosy patients but not in sera from uninfected controls or patients infected with other mycobacteria, including M. tuberculosis. The antibody response distinguished between the M. leprae lipid and the structurally related PGL from M. kansasii. Similar to serodiagnosis of MAC disease using GPL, this assay based on PGL antigen has considerable potential as a specific serodiagnostic test for infection with M. leprae $[83,84]$.

We determined the structure of the PGL derived from BCG (Tokyo 172 strain). The PGL produced by BCG is a so-called mycoside B (PGL-BCG), and its sugar moiety is different from that of the PGL produced by M. tuberculosis (PGL-tb). The PGL-BCG has only a 2-OMe-Rha branch elongated from the phenol moiety, although PGL-tb has it elongated to three sugar residues [85]. The composition of the PDIM in PGL is similar in both species. The MALDI-TOF MS spectrum of PGL-BCG showed m/z 1531 and other mass units at 14 Da intervals for $[\mathrm{M}+\mathrm{Na}]^{+}$as molecule-related ions in positive mode (Fig. 14). In addition, the MS/MS spectrum showed fragment ion peaks m/z 1371 based on the elimination of methyldeoxysugar; $\mathrm{m} / \mathrm{z}$ 1135, 1093, based on the elimination of the C26:0, C29:0 FAs; m/z 696 based on the elimination of both C26:0 and C29:0 FAs; and m/z 535 for the phenol phthiocerol that eliminated methyl-deoxysugar and C26:0, C29:0 FAs (Fig. 14).

Reed et al. demonstrated that PGL-tb inhibits the innate immune response. Loss of PGL-tb was responsible for an increase in the release of TNF- $\alpha$ and IL- 6 and IL-12 in vitro, and the PGL-tb-deficient mutant showed a phenotype with low virulence/pathogenicity [81]. The composition of the PDIM in PGL-BCG is similar to that in PGL-tb. Although purified PGL molecules by themselves had no effect on the activation of macrophages in vitro, we found that PGL suppressed the activation of murine bone marrow-derived macrophages elicited by total lipids. It is considered that the PGL may have a competitive inhibitory effect or mask the active site of other TLR2 agonistic lipid components, and decrease their activity.

\section{Phosphatidylinositol mannoside (PIM), lipomannan (LM), and lipoarabinomannan (LAM)}

PIMs and their multiglycosylated counterparts, LMs, and LAMs, are complex lipoglycans that are found ubiquitously in the envelopes of all mycobacterial species. Their structures originate from a phosphatidyl-myo-inositol (MPI) anchor, which is mannosylated to generate LM and further arabinosylated to give LAM [86]. The non-reducing termini of the arabinosyl side chains can be substituted by capping motifs, and LAMs are classified into three families. LAMs from slow growing mycobacteria bearing mannose caps, i.e. mono- or $(\alpha 1 \rightarrow 2)$-di- or trimannoside units, are designated as ManLAMs. In contrast, LAMs from fast growing mycobacteria capped by phospho-myo-inositol units and not capped at all, are termed PILAM and AraLAM, respectively [87]. LAMs and LMs exhibit a broad spectrum of 

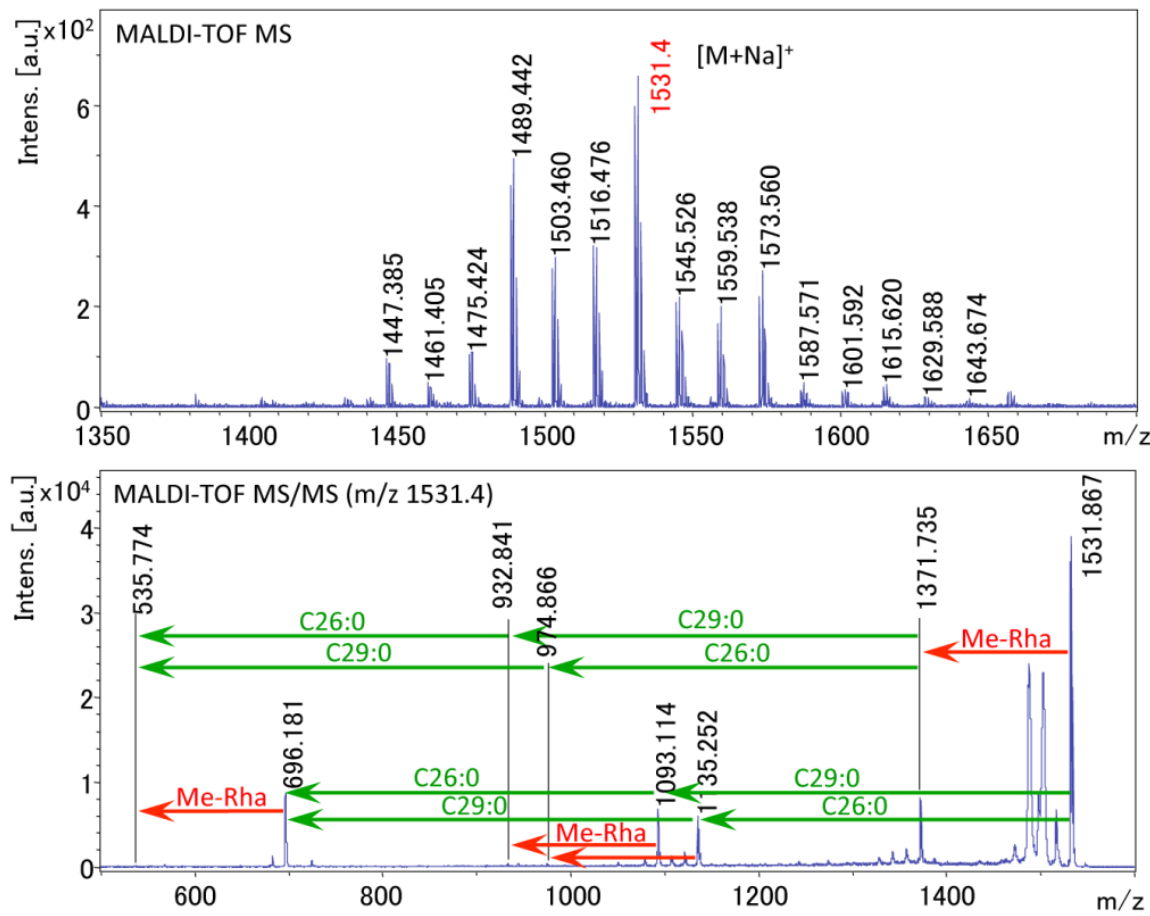

PGL Molecular Weight: 1508.5

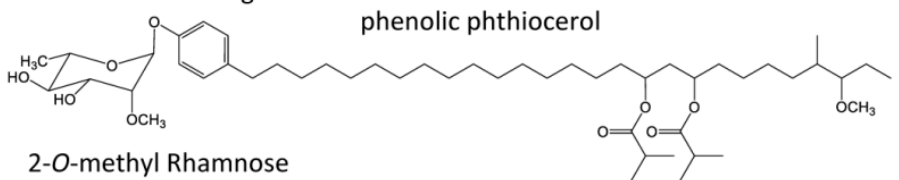

2-O-methyl Rhamnose

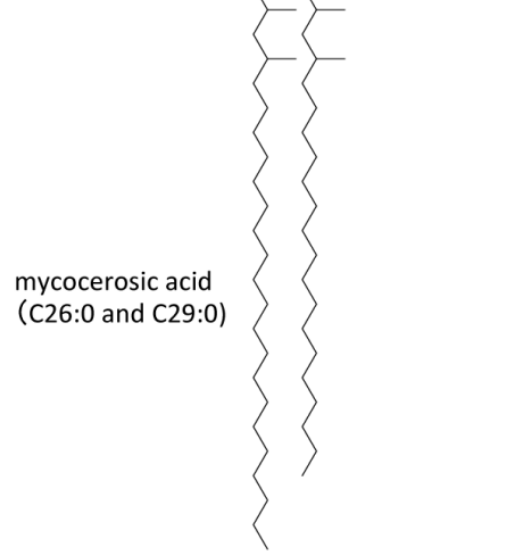

Figure 14. MALDI-TOF MS and MS/MS spectra of PGL derived from BCG Tokyo 172 strain, and proposed structure. 
immunomodulatory activities, including the ability to modulate the production of macrophage-derived Th1 pro-inflammatory cytokines, most commonly TNF- $\alpha$ and IL-12. The ManLAM from M. tuberculosis is involved in the inhibition of phagosome maturation, apoptosis, and IFN- $\gamma$ signaling in macrophages and IL-12 secretion of dendritic cells. ManLAMs contribute an immunosuppressive effect to the persistence of slow-growing mycobacteria in humans. In contrast, PILAMs are able to induce the release of a variety of proinflammatory cytokines. Recently it was reported that LMs from both pathogenic and nonpathogenic mycobacterial species, independent of their origin, are potent stimulators of TNF- $\alpha$, IL-8, and IL-12, and activate macrophages via TLR2 [88-90]. The ManLAM/LM balance might be important to host immune responses against mycobacteria.

PIMs are composed of a phsophatidylinositol and mannose moieties. PIMs have 4-6 mannoses, the third and fourth of which are acylated in some cases. PIM 2 containing two mannoses, a main component of mycobacterial cell walls, is highly immunogenic. Several biological functions have been recently attributed to PIMs. PIM2 was shown to recruit natural killer T cells, which play a role in the local granulomatous response [91, 92]. PIMs activate cells via TLR-2 [93]. PIM6 as well as the ManLAMs from M. leprae and $M$. tuberculosis are presented by antigen-presenting cells in the context of CD1b [17]. The phosphatidylinositol moiety plays a central role in the process of binding PIMs and ManLAMs to CD1b proteins.

\section{Conclusion}

Mycobacterial glycolipids are pleiotropic molecules and play key roles in both microbes and hosts by acting as structural components of cell walls and immunologically active substances. A better understanding of mycobacterial glycolipids will help us develop novel diagnostics, therapeutics, and prophylactics for mycobacterial diseases.

\section{Author details}

Nagatoshi Fujiwara

Department of Bacteriology, Osaka City University Graduate School of Medicine, Japan

\section{Acknowledgement}

This work was supported by grants from the Ministry of Education, Culture, Sports, Science and Technology of Japan, and the Japan Health Sciences Foundation.

\section{References}

[1] Koch R, (1884) Aetiologie der Tuberkulose. Mitt. k. Gesundheitsamt. 2: 1-88.

[2] WHO, (2011) WHO report 2011 Global Tuberculosis Control. http://www.who.int/tb/publications/global_report/2011/gtbr11_full.pdf. 
[3] Lee JH, Ammerman NC, Nolan S, Geiman DE, Lun S, Guo H, Bishai WR, (2012) Isoniazid resistance without a loss of fitness in Mycobacterium tuberculosis. Nat. Commun. 3: 753.

[4] Brennan PJ, Nikaido H, (1995) The envelope of mycobacteria. Annu. Rev. Biochem. 64: 29-63.

[5] Brennan PJ, (2003) Structure, function, and biogenesis of the cell wall of Mycobacterium tuberculosis. Tuberculosis (Edinb). 83: 91-97.

[6] Glickman MS, Jacobs WR, Jr., (2001) Microbial pathogenesis of Mycobacterium tuberculosis: dawn of a discipline. Cell. 104: 477-485.

[7] Russell DG, Mwandumba HC, Rhoades EE, (2002) Mycobacterium and the coat of many lipids. J. Cell. Biol. 158: 421-426.

[8] Fujiwara N, (1997) [Distribution of antigenic glycolipids among Mycobacterium tuberculosis strains and their contribution to virulence]. Kekkaku. 72: 193-205.

[9] Dmitriev BA, Ehlers S, Rietschel ET, Brennan PJ, (2000) Molecular mechanics of the mycobacterial cell wall: from horizontal layers to vertical scaffolds. Int. J. Med. Microbiol. 290: 251-258.

[10] Nikaido H, (2001) Preventing drug access to targets: cell surface permeability barriers and active efflux in bacteria. Semin. Cell. Dev. Biol. 12: 215-223.

[11] Aspinall GO, Chatterjee D, Brennan PJ, (1995) The variable surface glycolipids of mycobacteria: structures, synthesis of epitopes, and biological properties. Adv. Carbohydr. Chem. Biochem. 51: 169-242.

[12] Chatterjee D, Khoo KH, (2001) The surface glycopeptidolipids of mycobacteria: structures and biological properties. Cell Mol. Life Sci. 58: 2018-2042.

[13] Kobayashi K, Yoshida T, (1996) The immunopathogenesis of granulomatous inflammation induced by Mycobacterium tuberculosis. Methods. 9: 204-214.

[14] Beckman EM, Porcelli SA, Morita CT, Behar SM, Furlong ST, Brenner MB, (1994) Recognition of a lipid antigen by CD1-restricted alpha beta+ T cells. Nature. 372: 691694.

[15] Moody DB, Porcelli SA, Porcelli SA, Modlin RL, (2003) Intracellular pathways of CD1 antigen presentation. Nat. Rev. Immunol. 3: 11-22.

[16] Moody DB, Guy MR, Grant E, Cheng TY, Brenner MB, Besra GS, Porcelli SA, (2000) $\mathrm{CD} 1 \mathrm{~b}$-mediated $\mathrm{T}$ cell recognition of a glycolipid antigen generated from mycobacterial lipid and host carbohydrate during infection. J. Exp. Med. 192: 965-976.

[17] Sieling PA, Chatterjee D, Porcelli SA, Prigozy TI, Mazzaccaro RJ, Soriano T, Bloom BR, Brenner MB, Kronenberg M, Brennan PJ, et al., (1995) CD1-restricted T cell recognition of microbial lipoglycan antigens. Science. 269: 227-230.

[18] Kaneda K, Imaizumi S, Yano I, (1995) Distribution of C22-, C24- and C26-alpha-unitcontaining mycolic acid homologues in mycobacteria. Microbiol. Immunol. 39: 563-570.

[19] Nishiuchi Y, Baba T, Yano I, (2000) Mycolic acids from Rhodococcus, Gordonia, and Dietzia. J. Microbiol. Methods. 40: 1-9.

[20] Ueda S, Fujiwara N, Naka T, Sakaguchi I, Ozeki Y, Yano I, Kasama T, Kobayashi K, (2001) Structure-activity relationship of mycoloyl glycolipids derived from Rhodococcus sp. 4306. Microb. Pathog. 30: 91-99. 
[21] Butler WR, Guthertz LS, (2001) Mycolic acid analysis by high-performance liquid chromatography for identification of Mycobacterium species. Clin. Microbiol. Rev. 14: 704-726.

[22] Matsunaga I, Oka S, Fujiwara N, Yano I, (1996) Relationship between induction of macrophage chemotactic factors and formation of granulomas caused by mycoloyl glycolipids from Rhodococcus ruber (Nocardia rubra). J. Biochem. 120: 663-670.

[23] Matsunaga I, Naka T, Talekar RS, McConnell MJ, Katoh K, Nakao H, Otsuka A, Behar SM, Yano I, Moody DB, Sugita M, (2008) Mycolyltransferase-mediated glycolipid exchange in Mycobacteria. J. Biol. Chem. 283: 28835-28841.

[24] Fujita Y, Naka T, McNeil MR, Yano I, (2005) Intact molecular characterization of cord factor (trehalose 6,6'-dimycolate) from nine species of mycobacteria by MALDI-TOF mass spectrometry. Microbiology. 151: 3403-3416.

[25] Kaneda K, Sumi Y, Kurano F, Kato Y, Yano I, (1986) Granuloma formation and hemopoiesis induced by C36-48-mycolic acid-containing glycolipids from Nocardia rubra. Infect. Immun. 54: 869-875.

[26] Natsuhara Y, Oka S, Kaneda K, Kato Y, Yano I, (1990) Parallel antitumor, granulomaforming and tumor-necrosis-factor-priming activities of mycoloyl glycolipids from Nocardia rubra that differ in carbohydrate moiety: structure-activity relationships. Cancer Immunol. Immunother. 31: 99-106.

[27] Yano I, Tomiyasu I, Kaneda K, Kato Y, Sumi Y, Kurano S, Sugimoto N, Sawai H, (1987) Isolation of mycolic acid-containing glycolipids in Nocardia rubra and their granuloma forming activity in mice. J. Pharmacobiodyn. 10: 113-123.

[28] Yamagami H, Matsumoto T, Fujiwara N, Arakawa T, Kaneda K, Yano I, Kobayashi K, (2001) Trehalose 6,6'-dimycolate (cord factor) of Mycobacterium tuberculosis induces foreign-body- and hypersensitivity-type granulomas in mice. Infect. Immun. 69: 810815.

[29] Natsuhara Y, Yoshinaga J, Shogaki T, Sumi-Nishikawa Y, Kurano S, Kato Y, Kaneda K, Oka S, Yano I, (1990) Granuloma-forming activity and antitumor activity of newly isolated mycoloyl glycolipid from Rhodococcus terrae 70012 (Rt. GM-2). Microbiol. Immunol. 34: 45-53.

[30] Ishikawa E, Ishikawa T, Morita YS, Toyonaga K, Yamada H, Takeuchi O, Kinoshita T, Akira S, Yoshikai Y, Yamasaki S, (2009) Direct recognition of the mycobacterial glycolipid, trehalose dimycolate, by C-type lectin Mincle. J. Exp. Med. 206: 2879-2888.

[31] Brennan PJ, Goren MB, (1979) Structural studies on the type-specific antigens and lipids of the Mycobacterium avium, Mycobacterium intracellulare, Mycobacterium scrofulaceum serocomplex, Mycobacterium intracellulare serotype 9. J. Biol. Chem. 254: 4205-4211.

[32] Fujiwara N, Nakata N, Maeda S, Naka T, Doe M, Yano I, Kobayashi K, (2007) Structural characterization of a specific glycopeptidolipid containing a novel $\mathrm{N}$-acyl-deoxy sugar from Mycobacterium intracellulare serotype 7 and genetic analysis of Its glycosylation pathway. J. Bacteriol. 189: 1099-1108.

[33] Naka T, Nakata N, Maeda S, Yamamoto R, Doe M, Mizuno S, Niki M, Kobayashi K, Ogura H, Makino M, Fujiwara N, (2011) Structure and host recognition of serotype 13 glycopeptidolipid from Mycobacterium intracellulare. J. Bacteriol. 193: 5766-5774. 
[34] Fujiwara N, Nakata N, Naka T, Yano I, Doe M, Chatterjee D, McNeil M, Brennan PJ, Kobayashi K, Makino M, Matsumoto S, Ogura H, Maeda S, (2008) Structural analysis and biosynthesis gene cluster of an antigenic glycopeptidolipid from Mycobacterium intracellulare. J. Bacteriol. 190: 3613-3621.

[35] Nakata N, Fujiwara N, Naka T, Yano I, Kobayashi K, Maeda S, (2008) Identification and characterization of two novel methyltransferase genes that determine the serotype 12specific structure of glycopeptidolipids of Mycobacterium intracellulare. J. Bacteriol. 190: 1064-1071.

[36] Eckstein TM, Belisle JT, Inamine JM, (2003) Proposed pathway for the biosynthesis of serovar-specific glycopeptidolipids in Mycobacterium avium serovar 2. Microbiology. 149: 2797-2807.

[37] Heidelberg T, Martin OR, (2004) Synthesis of the glycopeptidolipid of Mycobacterium avium Serovar 4: first example of a fully synthetic C-mycoside GPL. J. Org. Chem. 69: 2290-2301.

[38] Maslow JN, Irani VR, Lee SH, Eckstein TM, Inamine JM, Belisle JT, (2003) Biosynthetic specificity of the rhamnosyltransferase gene of Mycobacterium avium serovar 2 as determined by allelic exchange mutagenesis. Microbiology. 149: 3193-3202.

[39] Eckstein TM, Inamine JM, Lambert ML, Belisle JT, (2000) A genetic mechanism for deletion of the ser2 gene cluster and formation of rough morphological variants of Mycobacterium avium. J. Bacteriol. 182: 6177-6182.

[40] Howard ST, Rhoades E, Recht J, Pang X, Alsup A, Kolter R, Lyons CR, Byrd TF, (2006) Spontaneous reversion of Mycobacterium abscessus from a smooth to a rough morphotype is associated with reduced expression of glycopeptidolipid and reacquisition of an invasive phenotype. Microbiology. 152: 1581-1590.

[41] Belisle JT, Klaczkiewicz K, Brennan PJ, Jacobs WR, Jr., Inamine JM, (1993) Rough morphological variants of Mycobacterium avium. Characterization of genomic deletions resulting in the loss of glycopeptidolipid expression. J. Biol. Chem. 268: 10517-10523.

[42] Bhatnagar S, Schorey JS, (2007) Exosomes released from infected macrophages contain Mycobacterium avium glycopeptidolipids and are proinflammatory. J. Biol. Chem.

[43] Schorey JS, Sweet L, (2008) The mycobacterial glycopeptidolipids: structure, function, and their role in pathogenesis. Glycobiology. 18: 832-841.

[44] Enomoto K, Oka S, Fujiwara N, Okamoto T, Okuda Y, Maekura R, Kuroki T, Yano I, (1998) Rapid serodiagnosis of Mycobacterium avium-intracellulare complex infection by ELISA with cord factor (trehalose 6, 6'-dimycolate), and serotyping using the glycopeptidolipid antigen. Microbiol. Immunol. 42: 689-696.

[45] Kitada S, Maekura R, Toyoshima N, Fujiwara N, Yano I, Ogura T, Ito M, Kobayashi K, (2002) Serodiagnosis of pulmonary disease due to Mycobacterium avium complex with an enzyme immunoassay that uses a mixture of glycopeptidolipid antigens. Clin. Infect. Dis. 35: 1328-1335.

[46] Kitada S, Maekura R, Toyoshima N, Naka T, Fujiwara N, Kobayashi M, Yano I, Ito M, Kobayashi K, (2005) Use of glycopeptidolipid core antigen for serodiagnosis of Mycobacterium avium complex pulmonary disease in immunocompetent patients. Clin. Diagn. Lab. Immunol. 12: 44-51. 
[47] Kitada S, Kobayashi K, Ichiyama S, Takakura S, Sakatani M, Suzuki K, Takashima T, Nagai T, Sakurabayashi I, Ito M, Maekura R, (2008) Serodiagnosis of Mycobacterium avium-complex pulmonary disease using an enzyme immunoassay kit. Am. J. Respir. Crit. Care Med. 177: 793-797.

[48] Maekura R, Okuda Y, Hirotani A, Kitada S, Hiraga T, Yoshimura K, Yano I, Kobayashi $\mathrm{K}$, Ito M, (2005) Clinical and prognostic importance of serotyping Mycobacterium aviumMycobacterium intracellulare complex isolates in human immunodeficiency virusnegative patients. J. Clin. Microbiol. 43: 3150-3158.

[49] Kitada S, Kobayashi K, Nishiuchi Y, Fushitani K, Yoshimura K, Tateishi Y, Miki K, Miki M, Hashimoto H, Motone M, Fujikawa T, Hiraga T, Maekura R, (2010) Serodiagnosis of pulmonary disease due to Mycobacterium avium complex proven by bronchial wash culture. Chest. 138: 236-237.

[50] Barrow WW, Davis TL, Wright EL, Labrousse V, Bachelet M, Rastogi N, (1995) Immunomodulatory spectrum of lipids associated with Mycobacterium avium serovar 8. Infect. Immun. 63: 126-133.

[51] Kano H, Doi T, Fujita Y, Takimoto H, Yano I, Kumazawa Y, (2005) Serotype-specific modulation of human monocyte functions by glycopeptidolipid (GPL) isolated from Mycobacterium avium complex. Biol. Pharm. Bull. 28: 335-339.

[52] Tassell SK, Pourshafie M, Wright EL, Richmond MG, Barrow WW, (1992) Modified lymphocyte response to mitogens induced by the lipopeptide fragment derived from Mycobacterium avium serovar-specific glycopeptidolipids. Infect. Immun. 60: 706-711.

[53] Takegaki Y, (2000) [Effect of serotype specific glycopeptidolipid (GPL) isolated from Mycobacterium avium complex (MAC) on phagocytosis and phagosome-lysosome fusion of human peripheral blood monocytes]. Kekkaku. 75: 9-18.

[54] Shimada K, Takimoto H, Yano I, Kumazawa Y, (2006) Involvement of mannose receptor in glycopeptidolipid-mediated inhibition of phagosome-lysosome fusion. Microbiol. Immunol. 50: 243-251.

[55] Danelishvili L, Wu M, Stang B, Harriff M, Cirillo S, Cirillo J, Bildfell R, Arbogast B, Bermudez LE, (2007) Identification of Mycobacterium avium pathogenicity island important for macrophage and amoeba infection. Proc. Natl. Acad. Sci. USA. 104: 1103811043.

[56] Khoo KH, Chatterjee D, Dell A, Morris HR, Brennan PJ, Draper P, (1996) Novel Omethylated terminal glucuronic acid characterizes the polar glycopeptidolipids of Mycobacterium habana strain TMC 5135. J. Biol. Chem. 271: 12333-12342.

[57] Bhatt A, Fujiwara N, Bhatt K, Gurcha SS, Kremer L, Chen B, Chan J, Porcelli SA, Kobayashi K, Besra GS, Jacobs WR, Jr., (2007) Deletion of kasB in Mycobacterium tuberculosis causes loss of acid-fastness and subclinical latent tuberculosis in immunocompetent mice. Proc. Natl. Acad. Sci. USA. 104: 5157-5162.

[58] Hakomori S, (1964) A rapid permethylation of glycolipid, and polysaccharide catalyzed by methylsulfinyl carbanion in dimethyl sulfoxide. J. Biochem. (Tokyo). 55: 205-208.

[59] Khoo KH, Jarboe E, Barker A, Torrelles J, Kuo CW, Chatterjee D, (1999) Altered expression profile of the surface glycopeptidolipids in drug-resistant clinical isolates of Mycobacterium avium complex. J. Biol. Chem. 274: 9778-9785. 
[60] Eckstein TM, Silbaq FS, Chatterjee D, Kelly NJ, Brennan PJ, Belisle JT, (1998) Identification and recombinant expression of a Mycobacterium avium rhamnosyltransferase gene $(r t f A)$ involved in glycopeptidolipid biosynthesis. J. Bacteriol. 180: 5567-5573.

[61] Krzywinska E, Schorey JS, (2003) Characterization of genetic differences between Mycobacterium avium subsp. avium strains of diverse virulence with a focus on the glycopeptidolipid biosynthesis cluster. Vet. Microbiol. 91: 249-264.

[62] Means TK, Wang S, Lien E, Yoshimura A, Golenbock DT, Fenton MJ, (1999) Human toll-like receptors mediate cellular activation by Mycobacterium tuberculosis. J. Immunol. 163: 3920-3927.

[63] Feng CG, Scanga CA, Collazo-Custodio CM, Cheever AW, Hieny S, Caspar P, Sher A, (2003) Mice lacking myeloid differentiation factor 88 display profound defects in host resistance and immune responses to Mycobacterium avium infection not exhibited by Toll-like receptor 2 (TLR2)- and TLR4-deficient animals. J. Immunol. 171: 4758-4764.

[64] Sweet L, Schorey JS, (2006) Glycopeptidolipids from Mycobacterium avium promote macrophage activation in a TLR2- and MyD88-dependent manner. J. Leukoc. Biol. 80: 415-423.

[65] Sweet L, Zhang W, Torres-Fewell H, Serianni A, Boggess W, Schorey J, (2008) Mycobacterium avium glycopeptidolipids require specific acetylation and methylation patterns for signaling through toll-like receptor 2. J. Biol. Chem. 283: 33221-33231.

[66] Goren MB, (1970) Sulfolipid I of Mycobacterium tuberculosis, strain H37Rv. II. Structural studies. Biochim. Biophys. Acta. 210: 127-138.

[67] Mougous JD, Petzold CJ, Senaratne RH, Lee DH, Akey DL, Lin FL, Munchel SE, Pratt MR, Riley LW, Leary JA, Berger JM, Bertozzi CR, (2004) Identification, function and structure of the mycobacterial sulfotransferase that initiates sulfolipid-1 biosynthesis. Nat. Struct. Mol. Biol. 11: 721-729.

[68] Pabst MJ, Gross JM, Brozna JP, Goren MB, (1988) Inhibition of macrophage priming by sulfatide from Mycobacterium tuberculosis. J. Immunol. 140: 634-640.

[69] Zhang L, English D, Andersen BR, (1991) Activation of human neutrophils by Mycobacterium tuberculosis-derived sulfolipid-1. J. Immunol. 146: 2730-2736.

[70] Converse SE, Mougous JD, Leavell MD, Leary JA, Bertozzi CR, Cox JS, (2003) MmpL8 is required for sulfolipid-1 biosynthesis and Mycobacterium tuberculosis virulence. Proc. Natl. Acad. Sci. USA. 100: 6121-6126.

[71] Rousseau C, Turner OC, Rush E, Bordat Y, Sirakova TD, Kolattukudy PE, Ritter S, Orme IM, Gicquel B, Jackson M, (2003) Sulfolipid deficiency does not affect the virulence of Mycobacterium tuberculosis $\mathrm{H} 37 \mathrm{Rv}$ in mice and guinea pigs. Infect. Immun. 71: 4684-4690.

[72] Okamoto Y, Fujita Y, Naka T, Hirai M, Tomiyasu I, Yano I, (2006) Mycobacterial sulfolipid shows a virulence by inhibiting cord factor induced granuloma formation and TNF-alpha release. Microb. Pathog. 40: 245-253.

[73] Gilleron M, Stenger S, Mazorra Z, Wittke F, Mariotti S, Bohmer G, Prandi J, Mori L, Puzo G, De Libero G, (2004) Diacylated sulfoglycolipids are novel mycobacterial 
antigens stimulating CD1-restricted $\mathrm{T}$ cells during infection with Mycobacterium tuberculosis. J. Exp. Med. 199: 649-659.

[74] Sirakova TD, Thirumala AK, Dubey VS, Sprecher H, Kolattukudy PE, (2001) The Mycobacterium tuberculosis pks2 gene encodes the synthase for the hepta- and octamethyl-branched fatty acids required for sulfolipid synthesis. J. Biol. Chem. 276: 16833-16839.

[75] Domenech P, Reed MB, Dowd CS, Manca C, Kaplan G, Barry CE, 3rd, (2004) The role of MmpL8 in sulfatide biogenesis and virulence of Mycobacterium tuberculosis. J. Biol. Chem. 279: 21257-21265.

[76] Kumar P, Schelle MW, Jain M, Lin FL, Petzold CJ, Leavell MD, Leary JA, Cox JS, Bertozzi CR, (2007) PapA1 and PapA2 are acyltransferases essential for the biosynthesis of the Mycobacterium tuberculosis virulence factor sulfolipid-1. Proc. Natl. Acad. Sci. USA. 104: 11221-11226.

[77] Daffe M, Laneelle MA, (1988) Distribution of phthiocerol diester, phenolic mycosides and related compounds in mycobacteria. J. Gen. Microbiol. 134: 2049-2055.

[78] Fournie JJ, Adams E, Mullins RJ, Basten A, (1989) Inhibition of human lymphoproliferative responses by mycobacterial phenolic glycolipids. Infect. Immun. 57: 3653-3659.

[79] Mehra V, Brennan PJ, Rada E, Convit J, Bloom BR, (1984) Lymphocyte suppression in leprosy induced by unique M. leprae glycolipid. Nature. 308: 194-196.

[80] Vachula M, Holzer TJ, Andersen BR, (1989) Suppression of monocyte oxidative esponse by phenolic glycolipid I of Mycobacterium leprae. J. Immunol. 142: 1696-1701.

[81] Reed MB, Domenech P, Manca C, Su H, Barczak AK, Kreiswirth BN, Kaplan G, Barry CE, 3rd, (2004) A glycolipid of hypervirulent tuberculosis strains that inhibits the innate mmune response. Nature. 431: 84-87.

[82] Tsenova L, Ellison E, Harbacheuski R, Moreira AL, Kurepina N, Reed MB, Mathema B, Barry CE, 3rd, Kaplan G, (2005) Virulence of selected Mycobacterium tuberculosis clinical isolates in the rabbit model of meningitis is dependent on phenolic glycolipid produced by the bacilli. J. Infect. Dis. 192: 98-106.

[83] Young DB, Buchanan TM, (1983) A serological test for leprosy with a glycolipid specific for Mycobacterium leprae. Science. 221: 1057-1059.

[84] zumi S, Fujiwara T, Ikeda M, Nishimura Y, Sugiyama K, Kawatsu K, (1990) Novel gelatin particle agglutination test for serodiagnosis of leprosy in the field. J. Clin. Microbiol. 28: 525-529.

[85] Simeone R, Leger M, Constant P, Malaga W, Marrakchi H, Daffe M, Guilhot C, Chalut C, (2010) Delineation of the roles of FadD22, FadD26 and FadD29 in the biosynthesis of phthiocerol dimycocerosates and related compounds in Mycobacterium tuberculosis. FEBS J. 277: 2715-2725.

[86] Hunter SW, Brennan PJ, (1990) Evidence for the presence of a phosphatidylinositol anchor on the lipoarabinomannan and lipomannan of Mycobacterium tuberculosis. J. Biol. Chem. 265: 9272-9279.

[87] Nigou J, Gilleron M, Puzo G, (2003) Lipoarabinomannans: from structure to biosynthesis. Biochimie. 85: 153-166. 
[88] Dao DN, Kremer L, Guerardel Y, Molano A, Jacobs WR, Jr., Porcelli SA, Briken V, (2004) Mycobacterium tuberculosis lipomannan induces apoptosis and interleukin-12 production in macrophages. Infect. Immun. 72: 2067-2074.

[89] Quesniaux VJ, Nicolle DM, Torres D, Kremer L, Guerardel Y, Nigou J, Puzo G, Erard F, Ryffel B, (2004) Toll-like receptor 2 (TLR2)-dependent-positive and TLR2-independentnegative regulation of proinflammatory cytokines by mycobacterial lipomannans. J. Immunol. 172: 4425-4434.

[90] Vignal C, Guerardel Y, Kremer L, Masson M, Legrand D, Mazurier J, Elass E, (2003) Lipomannans, but not lipoarabinomannans, purified from Mycobacterium chelonae and Mycobacterium kansasii induce TNF-alpha and IL-8 secretion by a CD14-toll-like eceptor 2-dependent mechanism. J. Immunol. 171: 2014-2023.

[91] Apostolou I, Takahama Y, Belmant C, Kawano T, Huerre M, Marchal G, Cui J, Taniguchi M, Nakauchi H, Fournie JJ, Kourilsky P, Gachelin G, (1999) Murine natural killer T(NKT) cells [correction of natural killer cells] contribute to the granulomatous eaction caused by mycobacterial cell walls. Proc. Natl. Acad. Sci. USA. 96: 5141-5146.

[92] Gilleron M, Ronet C, Mempel M, Monsarrat B, Gachelin G, Puzo G, (2001) Acylation state of the phosphatidylinositol mannosides from Mycobacterium bovis bacillus Calmette Guerin and ability to induce granuloma and recruit natural killer T cells. J. Biol. Chem. 276: 34896-34904.

[93] Jones BW, Means TK, Heldwein KA, Keen MA, Hill PJ, Belisle JT, Fenton MJ, (2001) Different Toll-like receptor agonists induce distinct macrophage responses. J. Leukoc. Biol. 69: 1036-1044. 